Journal of Advanced Research in Fluid Mechanics and Thermal Sciences

Journal homepage: www.akademiabaru.com/arfmts.html ISSN: 2289-7879

\title{
Investigations of Lift and Drag Performances on Neo-Ptero Micro UAV Models
}

\author{
Noor Iswadi Ismail ${ }^{1,}{ }^{*}$, Mahamad Hisyam Mahamad Basri ${ }^{1}$, Hazim Sharudin ${ }^{2}$, Zurriati Mohd Ali ${ }^{2}$, \\ Ahmad Aliff Ahmad Shariffuddin ${ }^{3}$, Nik Izwan Kamel ${ }^{3}$
Faculty of Mechanical Engineering, Universiti Teknologi Mara, Cawangan Pulau Pinang, Kampus Permatang Pauh, 13500 Permatang Pauh, Pulau Pinang, Malaysia
2 Faculty of Mechanical Engineering, Universiti Teknologi MARA, Masai, Johor, Malaysia
IFCON Technology (M) Sdn. Bhd, Taman Industri Meranti Jaya, 47120 Puchong, Selangor, Malaysia

\section{ARTICLE INFO}

Article history

Received 3 February 2021

Received in revised form 6 April 2021

Accepted 8 April 2021

Available online 12 July 2021

\section{Keywords:}

Aerodynamics; Micro-UAV; Lift coefficients; Drag coefficients; Vortex

\section{ABSTRACT}

This paper presents the investigation and comparison of the lift and drag performances between the Neo-Ptero micro-UAV variant models based on the virtual wind tunnel method. Despite its successful development and flight stability, the lift and drag coefficients characteristics of the Neo-Ptero model variations are still unknown. Mark 1 has the original NACA 0012 wing configuration while the Mark 2 Neo-Ptero model is a new proposed model with asymmetric BE50 airfoil wing configuration. Computational aerodynamic analysis was performed and focused on certain lift and drag coefficient characteristics. Lift coefficient results showed that Mark 2 has better overall lift characteristics such as zero-lift angle, maximum lift magnitude, stall angle lift magnitude and percentage of lift increment. In contrast, the Mark 2 model experienced higher drag coefficient magnitude and a significantly higher percentage of drag than the Mark 1. Nevertheless, the lift-to-drag ratio magnitude for Mark 2 was greater than Mark 1 but limited at the early $\alpha$ region. Mark 2 had produced the maximum lift-to-drag ratio magnitude of 14.91 which is marginally better than Mark 1.

\section{Introduction}

A micro unmanned aerial vehicle (micro-UAV) is a small unmanned aircraft capable of being fully autonomous or controlled on the ground by an operator [1]. The wings of a micro-UAV are classified into two types, namely fixed-wing and rotary-wing [2]. Given its wider coverage area and payload compatibility, a fixed-wing micro-UAV is more common than the rotary-wing type [1]. The fixed-wing configuration consists of two types, known as micro-UAV with a conventional tail and tailless microUAV.

Neo-Ptero is one of the micro-sized UAV aircraft models designed by IFCON (Malaysia) Pvt. Ltd., as shown in Figure 1 [3]. This developed Neo-Ptero micro-UAV, known as Mark 1 Neo-Ptero, has

\footnotetext{
* Corresponding author.

E-mail address: iswadi558@uitm.edu.my
}

https://doi.org/10.37934/arfmts.84.2.5062 
adopted a symmetrical NACA0012 airfoil type for the tailless wing configuration [2]. The tailless micro-UAV prototype has been conceived and developed based on the CNC foam cutter machine. Neo-Ptero fuselage and wing materials used are the expanded polypropylene (EPP) foam with low density and high elasticity, which contribute to the vehicle's lightweight and flexible wing structure. 3D printing method based on the ABS plastic content has been also used in the manufacture of Mark 1 Neo-Ptero micro-UAV model. The ready-to-fly Mark 1 Neo-Ptero prototype has been equipped with standard electronic flight control components for flight testing, including an electronic speed controller, a transmitter, a brushless motor, a propeller, a battery, and micro servos. Elevon control configurations have been also adopted for Mark 1 Neo-Ptero micro-UAV model at the trailing edge of the wings. The left and right elevon deflections of the micro-UAV model provide the primary control function for pitching, yawing, and rolling motions. Based on the initial actual flight test, the Mark 1 Neo-Ptero prototype has demonstrated a promising ability to fly in stable conditions with minimal input from the pilot [3].
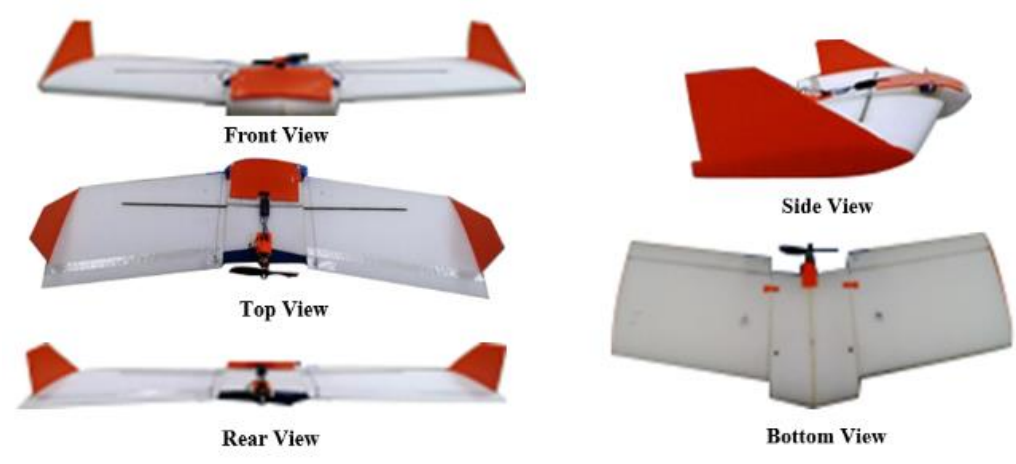

Fig. 1. Mark 1 Neo-Ptero micro-UAV [3]

Despite its rapid implementation and encouraging flight stability, the aerodynamic performance of the Neo-Ptero, particularly in terms of its lift and drag distributions remains unknown. The original Neo-Ptero micro-UAV model (designated as Mark 1) has the original wing profile of NACA 0012 while a new proposed Neo-Ptero micro-UAV model Mark 2 model has a new airfoil wing configuration of BE50 wing profile. BE50 is an asymmetrical airfoil that is suitable for low subsonic and free flight micro size aircraft [4,5]. Despite BE50 compatibility with micro-size aircraft, the profile has never been implemented on the Neo-Ptero wing configuration. Thus, the aerodynamic performance of BE50 on Neo-Ptero micro-UAV platform is also still unknown. Thus, the main objective of this study is to investigate and compare the lift and drag characteristics between the original Neo-Ptero Mark 1 and a new proposed Neo-Ptero Mark 2 model. To achieve the study objective, a computational aerodynamic analysis based on virtual wind tunnel method was fully employed to evaluate the aerodynamic performances of the Mark 1 and Mark 2 Neo-Ptero prototypes. The virtual wind tunnel method was implemented using the commercial CFD software package. The analysis outcomes were characterized and compared in terms of the main lift $\left(C_{L}\right)$ and drag $\left(C_{D}\right)$ characteristics of the Mark 1 and Mark 2 Neo-Ptero models. Improving these distributions over the Neo-Ptero model may further improve its power usage for the micro-UAV and prolong its flight endurance $[1,6,7]$.

\section{Methodology}

\subsection{D Design of Neo-Ptero and Dimension}

To ensure the consistency of the dimensions of Mark 1 and Mark 2 Neo-Ptero models used in the virtual wind tunnel analysis, the original 3D drawing of the micro-UAV for both designs was imported 
into the virtual wind tunnel analysis modules. Figure 2 shows the 3D drawing of the Mark 1 and Mark 2 Neo-Ptero micro-UAV designs. The Mark 1 and Mark 2 Neo-Ptero micro-UAV models have identical fuselage components and $20^{\circ}$ swept-backward wings. The mass and aspect ratio for both models were maintained at $1.3 \mathrm{~kg}$ and 3.46 , respectively.
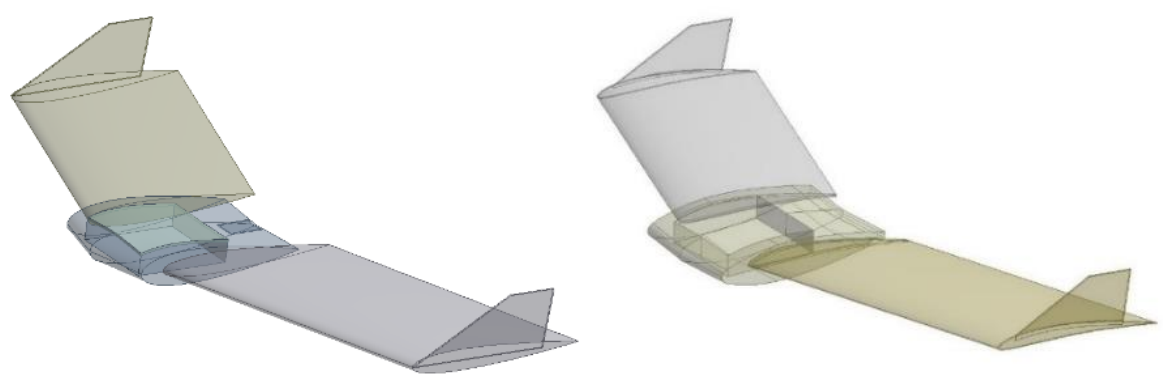

Fig. 2. Mark 1 (Left) and Mark 2 (Right) Neo-Ptero micro-UAV 3D designs

The fuselage dimension for both configurations was retained as it is based on the shape of NACA0012. The root and tip chords of Mark 1 and Mark 2 were kept at $341.84 \mathrm{~mm}$. The original dimension of the wingtips on each wing edge was also retained. The main difference between the Mark 1 and Mark 2 Neo-Ptero models was the airfoil type built for the wings. The Mark 1 Neo-Ptero has the original design of the NACA0012 symmetrical airfoil. In comparison, the Mark 2 Neo-Ptero has a new wing set with the shape of BE50 cambered airfoil. For this virtual wind tunnel analysis, the control surfaces on both wings and models were set at their neutral positions. The propeller and motor mounting components were intentionally removed from the $3 \mathrm{D}$ drawing to avoid the flow complexity and aerodynamics influences of the components [8]. Such conditions ensured that the aerodynamic outcomes were solely provided by the fuselage-wing configurations of the Neo-Ptero model. Figure 3 presents the basic dimensions of Mark 1 and Mark 2 Neo-Ptero micro-UAV models.

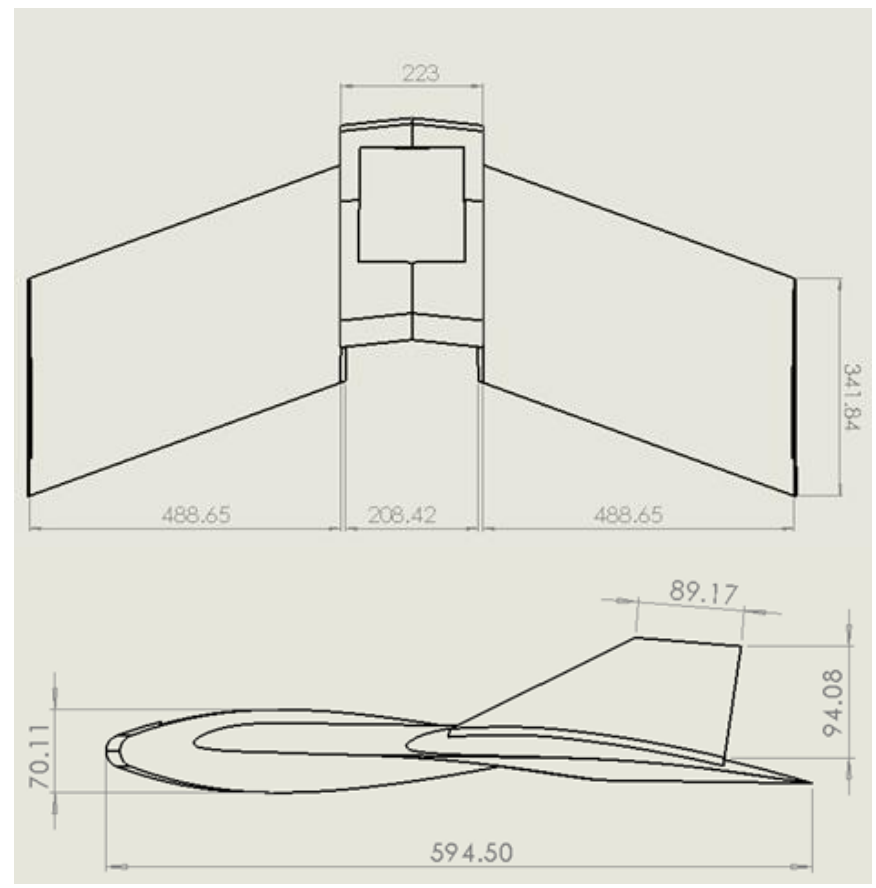

Fig. 3. Neo-Ptero micro-UAV dimensions in millimeters 


\subsection{Airflow Domain and Mesh Generation}

The airflow domain, as shown in Figure 4, was built around both Neo-Ptero models according to the total chordwise aircraft length $(C=594.5 \mathrm{~mm})$ as proposed by $[9,10]$. Only half of the airflow domain and the Neo-Ptero models were implemented in the virtual wind tunnel analysis to avoid computational burden [11]. The airflow domain and the Neo-Ptero model were integrated as one to ensure that the mesh-conforming characteristics were accomplished the surface boundaries. Unstructured hybrid of 3D mesh and inflation layers were fully developed with the first cell above the airplane surface, which was maintained at $y+$ value below 1 . The results of the grid-independent study showed that the optimized grid (Figure 5) for Mark 1 and Mark 2 Neo-Ptero prototypes achieved approximately 1,181,000 elements.

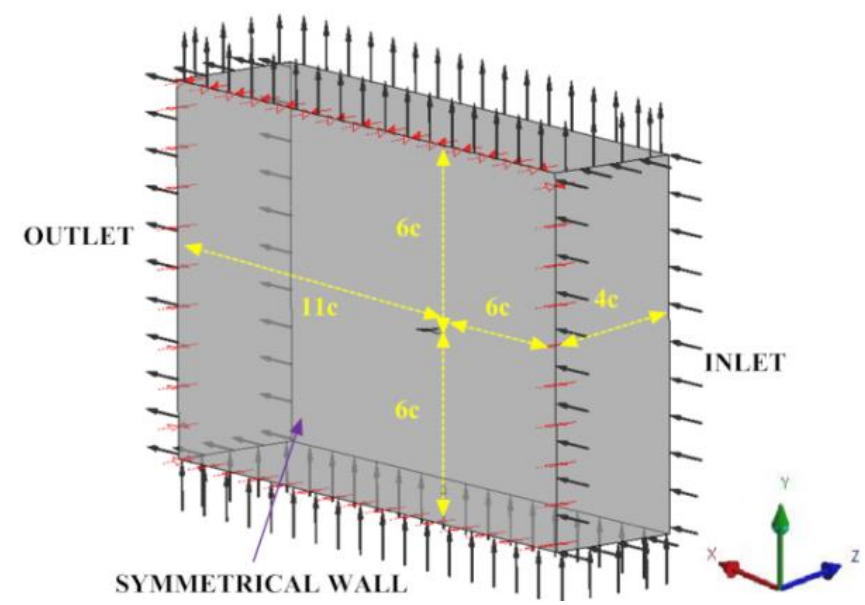

Fig. 4. Airflow domain built around Neo-Ptero model

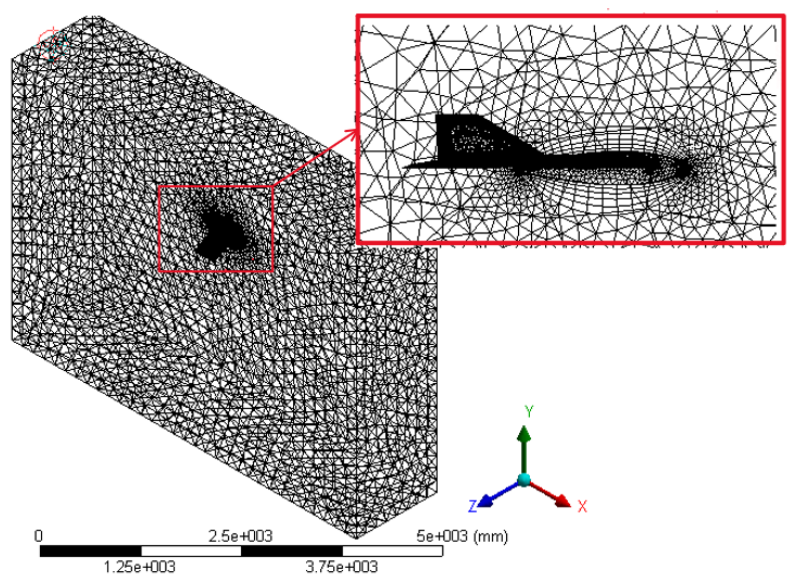

Fig. 5. Optimized grid on airflow domain surrounding the Neo-Ptero model

\subsection{Boundary Conditions}

The angle of attack $(\alpha)$ variation was set from $-10^{\circ}$ to $22^{\circ}$ with an interval of $2^{\circ}$ for Mark 1 and Mark 2 Neo-Ptero models. The inlet velocity was set to be similar to the actual flight test speed of the Neo-Ptero, which was averaged at $14 \mathrm{~m} / \mathrm{s}$. A no-slip surface and an automatic wall function were fully enforced on the surface model to capture the viscous effect on the Neo-Ptero surfaces 
satisfactorily. The simulations were conducted under steady-state conditions with incompressible flow Navier-Stokes equations (RANS) implemented in the solver. The shear stress turbulence (SST) model was adopted to solve the turbulence problems and to ensure that the stall phenomenon was satisfactorily captured at the variation of angles. The turbulence intensity was assumed to be at low condition with a magnitude of $5 \%$. The magnitude of the convergence control (residual below $\left.1.0 \times 10^{-6}\right)$ and aerodynamic coefficient monitors were used in the computation to ensure simulation convergence and prediction accuracy.

\section{Results}

\subsection{Lift Coefficient $\left(C_{L}\right)$ Characteristics}

The results of $C_{L}$ for Mark 1 and Mark 2 Neo-Ptero micro-UAV models are presented in Figure 6. As commonly found in the lift distribution results, both Neo-Ptero models exhibited almost a linear $C_{L}$ curve towards the increment of $\alpha$ magnitude. Only a slightly non-linear curve was apparent at $\alpha$ magnitude between $-10^{\circ}$ and $0^{\circ}$. However, as the $\alpha$ magnitude increased (at $\alpha=0^{\circ}$ to $\alpha=14^{\circ}$ ), the $C_{L}$ curves performed almost a linear increment. Both $C_{L}$ curves tended to plateau starting from $15^{\circ}$ before the curves reached their peak around $\alpha$ magnitude between $16^{\circ}$ and $18^{\circ}$. The $C_{L}$ curves consistently demonstrated a sudden decline of $C_{L}$ magnitude after the $C_{L}$ peak. By comparing the $C_{L}$ curves between Mark 1 and Mark 2, the results showed that the Mark 2 Neo-Ptero micro-UAV prototype produced higher $C_{L}$ curves than the Mark 1 model.

To elucidate these $C_{L}$ results, a detailed analysis was conducted to characterize the main $C_{L}$ performances between Mark 1 and Mark 2 Neo-Ptero micro-UAV models in terms of zero-lift angle of attack $\left(\alpha_{\mathrm{L}=0}\right)$, maximum $C_{\mathrm{L}}\left(\mathrm{C}_{\mathrm{Lmax}}\right)$ and stall angle $\left(\alpha_{\text {stall }}\right)$ magnitudes. A comparison was also made on the distribution of $C_{L}$ magnitude and percentage of $C_{L}$ increment between Mark 1 and Mark 2 NeoPtero models.

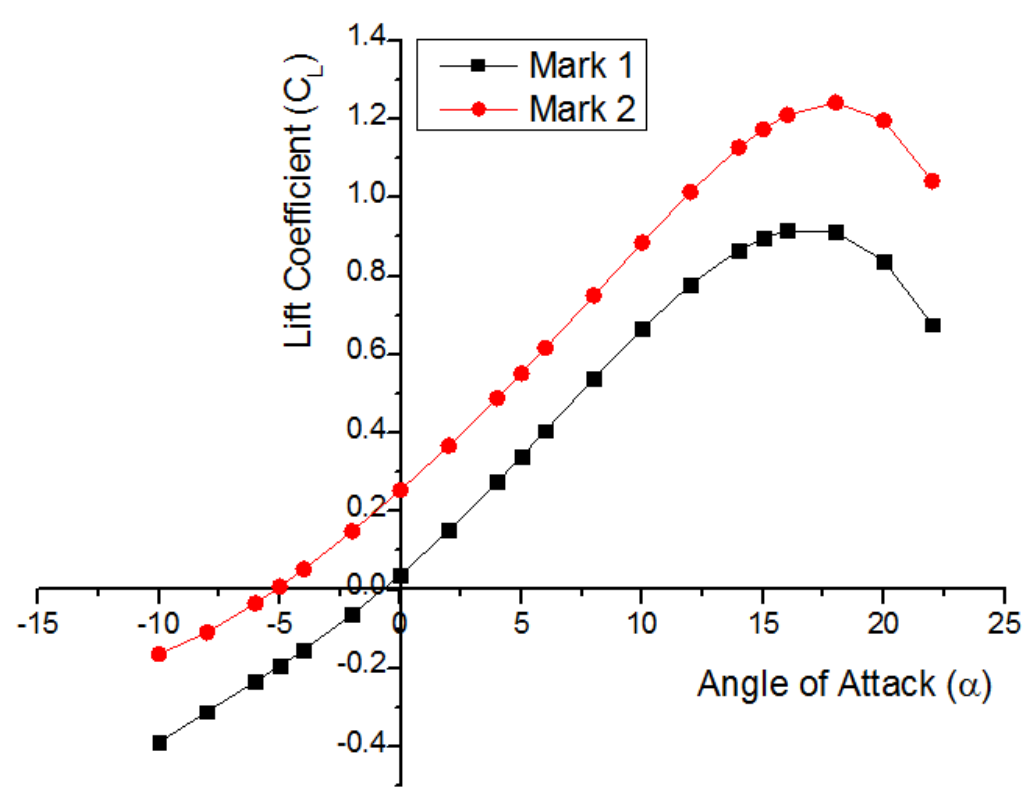

Fig. 6. $C_{L}$ performances of Neo-Ptero micro-UAV

Focusing on the $\alpha_{\mathrm{L}=0}$ characteristics, the result revealed that Mark 1 produced the magnitude of the zero-lift angle of the attack close to $0^{\circ}$, while Mark 2 produced $\alpha_{\mathrm{L}=0}$ at five degrees earlier than Mark 1 at $\alpha_{\mathrm{L}=0}=-5^{\circ}$. In terms of $C_{\mathrm{Lmax}}$ performance, Mark 2 benevolently generated $C_{\mathrm{Lmax}}$ magnitude $\left(C L_{\max }=1.24166\right)$, which was $35.6 \%$ higher than Mark $1\left(C_{\operatorname{Lmax}}=0.91566\right)$. Mark 2 also impressively 
produced better $\alpha_{\text {stall }}$ performances by delaying the stall angle at $18^{\circ}$, which was $2^{\circ}$ higher than Mark $1\left(\alpha_{\text {stall }}=16^{\circ}\right)$. By comparing the overall $C_{L}$ magnitude at low $\alpha$ stage (between $-10^{\circ}$ to $\left.2^{\circ}\right)$, the analysis showed that Mark 2 produced $C_{L}$ magnitude which was $28 \%$ higher than the Mark 1 on average. This favorable trend of Mark 2 continued at medium $\alpha$ stage (between $2^{\circ}$ to $10^{\circ}$ ), where it generated $C_{L}$ magnitude of $68 \%$ higher than Mark 1 on average. At high $\alpha$ stage (between $10^{\circ}$ to $16^{\circ}$ ), Mark 2 was able to exhibit an advantage in which the model produced $C_{L}$ magnitude which was $31 \%$ better than Mark 1 on average.

Based on the $C_{L}$ increment analysis, the results exhibited that Mark 2 also had better $C_{L}$ increment than Mark 1 at most of $\alpha$ stage. At $\alpha$ angle between $2^{\circ}$ and $10^{\circ}$, Mark 2 generated approximately $C_{L}$ increment of $36.1 \%$ on average for every $2^{\circ}$ of $\alpha$ increment. However, the advantages of Mark 2 in $C_{L}$ increment were reduced to $8.5 \%$ on average at $\alpha$ angle between $10^{\circ}$ and $16^{\circ}$.

The $C_{L}$ results demonstrated that Mark 2 has significant advantages in providing better lift characteristics, especially in the $\alpha_{\mathrm{L}=0}, C_{\mathrm{Lmax}}$, and $\alpha_{\text {stall }}$ magnitudes. Mark 2 also exhibited improvement in the overall $C_{L}$ magnitude and the percentage of the $C_{L}$ increment in most $\alpha$ stages. The improvement in the overall $C_{L}$ characteristics resulted from the airfoil changes implemented in the Mark 2 Neo-Ptero model, which is commonly found between cambered and symmetrical airfoil $[12,13]$. The cambered airfoil, as found in Mark 2 model, produced a differential change in the momentum of the flow around the airfoil, which caused differences in the pressure resulting from lift improvement $[9,12]$. This significant finding was justified through the investigations of pressure coefficient distribution conducted on the upper wing surfaces for both models as shown in Figure 7. The results were depicted at half wing and model's respective angle based on the $\alpha_{\mathrm{L}=0,} \alpha=10^{\circ}$ and $\alpha_{\text {stall }}$ magnitudes.

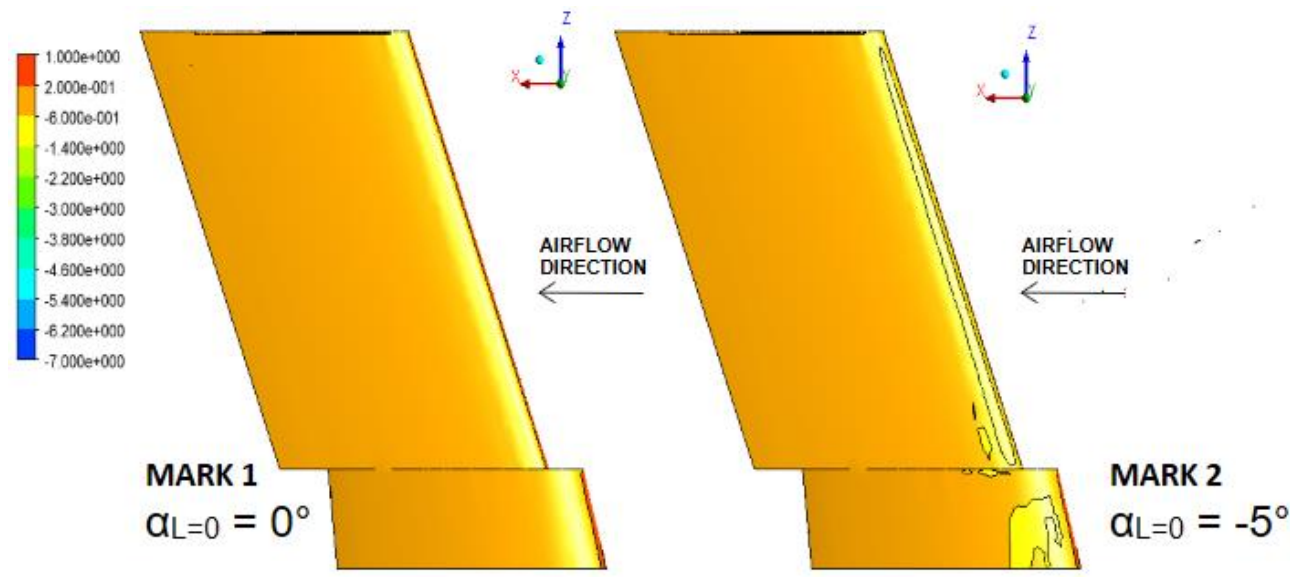

Fig. 7. Pressure coefficient distribution on upper wing surfaces at $\alpha_{\mathrm{L}=0}$ (top), $\alpha=10^{\circ}$ (middle) and $\alpha_{\text {stall }}$ angle (bottom) on Mark 1 (left) and Mark 2 (right)

At the $\alpha_{\mathrm{L}=0}$ angle condition, there were insignificant differences in pressure coefficient distributions found on both models. Such conditions reflected the identical zero-lift magnitude produced by both models at their respective $\alpha_{\mathrm{L}=0}$ angles. However, both models produced more distinguished difference in pressure coefficient distributions at $\alpha=10^{\circ}$. At this $\alpha$ stage, a low-pressure coefficient area with magnitude between $\mathrm{C} p=-0.6$ to -5.4 started to intensify near the wing leadingedge area. Observation showed that the low-pressure coefficient coverage area on Mark 2 surface is slightly larger than Mark 1. Furthermore, Mark 2 had a lower-pressure coefficient area with magnitude of $C p=-4.5$ to -5.4 (indicated by a light blue color area) concentrated at the wing leading edge. Such conditions are presumed to contribute into better $C_{L}$ performance produced by Mark 2 . Mark 2 produced better $C_{L}$ magnitude at this very $\alpha=10^{\circ}$ with $C_{L}=0.8850$ which is about $33 \%$ higher 
than Mark 1 at $C_{L}=0.6656$. At $\alpha_{\text {stall }}$ angle, more significant difference in pressure coefficient distributions was found between Mark 1 and Mark 2 models. A notable very low-pressure coefficient magnitude area (indicated by $\mathrm{Cp}$ magnitude below -0.6) had covered almost half of the wings. Moreover, a very low-pressure coefficient distributions area with $\mathrm{Cp}$ magnitude below -7.0 (indicated by dark blue color area) is spotted at the wing's leading on both models. Observation clearly showed that Mark 2 had more obvious and intensified dark blue area than Mark 1 particularly near wing leading edge area. These results had provided evidence behind the superior $C_{\text {Lmax }}$ magnitude produced by the Mark 2 model. The differences in the pressure coefficient distributions area found on Mark 2 had resulted into its lift improvement. At this very stall angle, Mark 2 produced about 35\% higher $C_{\text {Lmax }}$ magnitude than Mark 1 model.

\subsection{Drag Coefficient $\left(C_{D}\right)$ Characteristics}

The $C_{D}$ results for Mark 1 and Mark 2 Neo-Ptero micro-UAV models are presented in Figure 8 . In general, the $C_{D}$ curves for both wings have similar performances throughout the $\alpha$ region. Each curve started almost similar with $C_{D}$ value at $\alpha=-10^{\circ}$ before reaching its minimum value at $\alpha \approx-2^{\circ}$ to $0^{\circ}$. Then, the $C_{D}$ curves for both wings drastically increased with the increment of $\alpha$ exceeding the stall angle.

A detailed analysis was conducted to characterize the main $C_{D}$ attributes of Mark 1 and Mark 2 Neo-Ptero models. The analysis focused on the difference of certain magnitudes, such as the minimum $C_{D}\left(C_{D m i n}\right)$, overall $C_{D}$ magnitude and percentage of $C_{D}$ increment between the Neo-Ptero models.

Based on minimum $C_{D}$ magnitude, the results showed that both models produced almost similar $C_{D \text { min }}$ at 0.014 . However, Mark 2 induced the $C_{\text {Dmin }}$ magnitude at $2^{\circ}$ earlier than Mark $1\left(\alpha=0^{\circ}\right)$. In terms of the overall $C_{D}$ magnitude, the findings demonstrated that Mark 2 induced a slightly higher $C_{D}$ magnitude at $8 \%$ than Mark 1 in the low $\alpha$ region $\left(-10^{\circ}\right.$ to $\left.0^{\circ}\right)$. However, this percentage drastically increased to $62 \%$ in the $\alpha$ region between $2^{\circ}$ to $10^{\circ}$.

In the $\alpha$ region from $10^{\circ}$ to $16^{\circ}$, Mark 2 still produced higher $C_{D}$ magnitude than Mark 1 with lower percentage of $39 \%$. Such malevolent performances found in Mark 2 were persistent in the $C_{D}$ increment attribute, especially in the medium a region $\left(2^{\circ}\right.$ to $\left.10^{\circ}\right)$. In this $\alpha$ region, Mark 2 induced $C_{D}$ increment, which was $5 \%$ higher than Mark 1 . However, in other $\alpha$ regions $\left(\alpha=-10^{\circ}\right.$ to $0^{\circ} \& \alpha=$ $10^{\circ}$ to $16^{\circ}$ ), Mark 2 benevolently produced $C_{D}$ increment of $5 \%$ lower than Mark 1.

Analysis of the $C_{D}$ attributes showed that Mark 2 also had disadvantages. Mark 2 induced higher $C_{D}$ magnitude and greater $C_{D}$ increment percentage than Mark 1 . Such condition was presumed due to more significant lift performances generated by Mark 2 as shown in the previous section. More significant lift coefficient entails greater lift-dependent drag component known as the induced drag coefficient $[16,17]$. According to previous research by Hoang and Bui [15], the wingtip vortex core region also plays a vital role in generating high drag distribution on low-aspect-ratio wings. The tip vortex core region prohibits low drag conditions by recirculating, thus creating bubble vortices and inducing high 3D flow at the wingtip, which in turn creates strong and intense drag attributes [15][16]. From this theory, an initial tip vortex study was conducted to clarify the tip vortex core contribution to the drag performances of the Neo-Ptero models. 


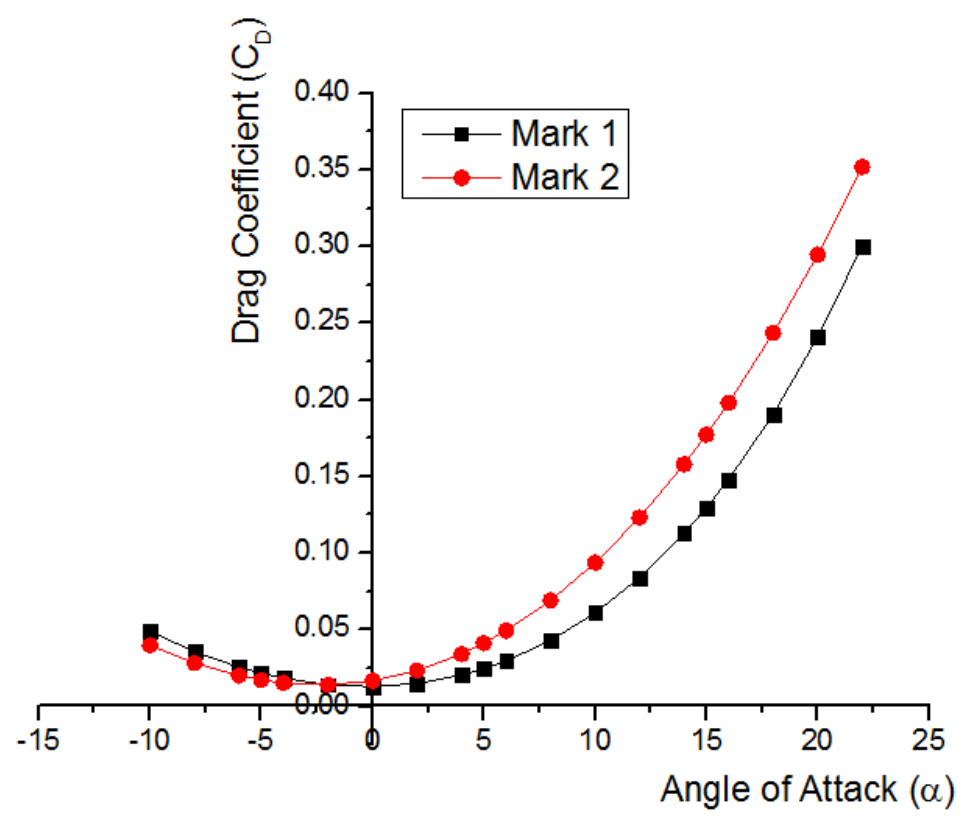

Fig. 8. $C_{D}$ performances of the Neo-Ptero micro-UAV

Figure 9 presents the 3D tip vortex structures on the Neo-Ptero prototypes viewed from the top of the wing at various $\alpha$ angles. The visualization of 3D vortex structures was based on the $Q$ criterion magnitude set at $0.025[9,17]$. A clear tip vortex structure (visualized as purple-colored flow) found on each wing tip started at the wingtip leading edge and flow downstream towards the wing tip trailing edge. The vortex structure drifted downstream at the rear wing as a vortex core region. An approximation measurement method was used as proposed by Ismail et al., [19] to elucidate the strength of the vortex core region on each wing. The tip vortex core dimension was approximately measured based on relative measurement to the wing chord length (C). This method used an approximate length of the vortex core region to indicate the vortex core intensity. A more extended vortex core region indicates greater vortex core intensity, which consequently contributes to higher induced drag generation [20]. From Figure 9 , at $\alpha$ between $-10^{\circ}$ to $-5^{\circ}$, there is only a slight difference in tip vortex sizes generated by both models. Mark 1 had a slightly longer and larger tip vortex core $(0.22 \mathrm{C}$ to $0.18 \mathrm{C})$ than Mark $2(0.2 \mathrm{C}$ to $0.08 \mathrm{C})$ at this $\alpha$ stages. However, these tip vortex conditions had contributed to a minimal difference in $C_{D}$ magnitude where both models had almost similar $C_{D}$ magnitude as indicated at this early $\alpha$ stage (shown in Figure 8). At $C_{D m i n}$ angle (Mark $1 \alpha=0^{\circ}$ and Mark $2 \alpha=-2^{\circ}$ ), both models consistently showed unclear and insignificant tip vortex core generations. Therefore, one can expect the tip vortex core region that creates strong and intense drag attributes were kept at minimal influence at this stage. Thus, a similar $C_{D m i n}$ magnitude was produced by both models as shown in Figure 8.

At $\alpha=10^{\circ}$, the tip vortex core found on both models becomes more obvious and distinguished. The tip vortex core size for Mark 2 and Mark 1 is about $0.6 \mathrm{C}$ and $0.35 \mathrm{C}$, respectively. At this point, the tip vortex core region which creates strong and large drag attributes were at significant influence. Such attributes reflected into the greater $C_{D}$ magnitude found at this $\alpha$ stage as shown in Figure 8 . Furthermore, Mark 2 has greater tip vortex structure than Mark 1 which signifies a larger induced drag influenced which consequently produced more significant $C_{D}$ attributes on the model. 

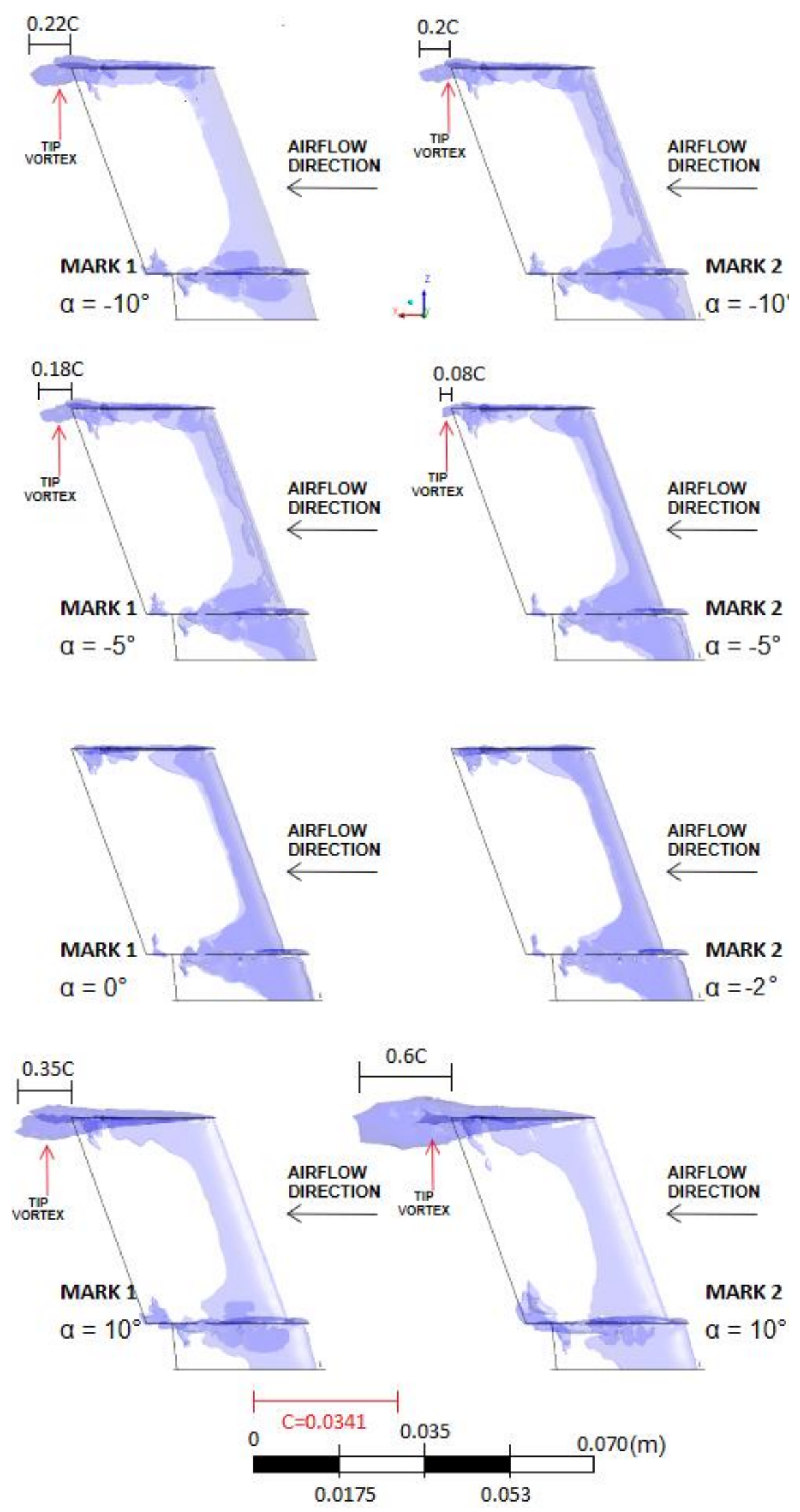

Fig. 9. 3D tip vortex structures at $\alpha=-10^{\circ},-5^{\circ}, C_{D m i n}$ angle and $10^{\circ}$ on Mark 1 (left) and Mark 2 (right) 


\subsection{Aerodynamic Efficiency $\left(C_{L} / C_{D}\right)$ Performances}

In aerodynamics, the magnitude of the lift-to-drag ratio $\left(C_{L} / C_{D}\right.$ or $\left.L / D\right)$ is commonly used to indicate the level of aerodynamic efficiency for an aircraft during its movement through the air [21]. Greater $C_{L} / C_{D}$ ratio magnitude is considerably one of the major goals in aircraft design. Figure 10 presents the $C_{L} / C_{D}$ performance for Mark 1 and Mark 2 Neo-Ptero micro-UAV s. The result showed that the overall $C_{L} / C_{D}$ curve trends for Mark 1 and Mark 2 exhibited almost similar performances throughout the $\alpha$ region. Both curves started with an increase in $C_{L} / C_{D}$ magnitude in the early $\alpha$ region $\left(-10^{\circ}\right.$ to $\left.2^{\circ}\right)$ and reached their peak (known as the maximum $C_{L} / C_{D}$ magnitude, $\left.C_{L} / C_{D \text { max }}\right)$ at $\alpha=2^{\circ}$ to $5^{\circ}$. Then, both curves depicted a consistent drastic decrease in $C_{L} / C_{D}$ magnitude at higher $\alpha$ angle stage $\left(5^{\circ}\right.$ to $\left.22^{\circ}\right)$. Despite the similarity found in the overall trend of $C_{L} / C_{D}$ curves, the $C_{L} / C_{D}$ curve for Mark 2 was located at a slightly higher position than Mark 1, especially at the $\alpha$ region between $-10^{\circ}$ and $2^{\circ}$. In this $\alpha$ region, Mark 2 was able to induce $C_{L} / C_{D}$ magnitude, which was $60 \%$ higher than Mark 1 on average. Mark 2 reached its maximum $C_{L} / C_{D}$ magnitude $\left(C_{L} / C_{D \max }\right)$ at $\alpha=2^{\circ}$ of 14.91 , which was approximately $4.7 \%$ higher than Mark 1 . However, Mark 1 was able to reach its $C_{L} / C_{D m a x}$ magnitude $\left(C_{L} / C_{D \text { max }}=14.24\right)$ at a slightly higher angle of $5^{\circ}$. As the $\alpha$ increased beyond $5^{\circ}$, Mark 1 and Mark 2 experienced a significant decline in $C_{L} / C_{D}$ magnitude. At this $\alpha$ stage, Mark 2 obtained a decrease of $13.2 \%$ in $C_{L} / C_{D}$ on average for every increment of $\alpha$ by $2^{\circ}$. Mark 1 also obtained $C_{L} / C_{D}$ decline of $12.4 \%$, which was close to that of Mark 2 within the same $\alpha$ region $\left(\alpha>5^{\circ}\right)$.

According to these $C_{L} / C_{D}$ performances, Mark 2 has huge advantages (60\% higher than Mark 1 ) in the overall magnitude of aerodynamic efficiency, especially at the early $\alpha$ stage $\left(-10^{\circ}\right.$ to $\left.2^{\circ}\right)$. This could be due to the significant advantage in the $C_{L}$ magnitude produced by Mark 2 (at this $\alpha$ stage), where it was able to induce $C_{L}$ magnitude of $28 \%$ on average better than Mark 1 (Figure 6 ). Such condition also contributed to a minor difference (8\%) in the $C_{D}$ magnitude found between Mark 1 and Mark 2 at this $\alpha$ stage (Figure 8). However, the beneficial trend achieved climax at $\mathrm{C}_{\mathrm{L}} / \mathrm{C}_{\mathrm{Dmax}}$ magnitude, where Mark 2 marginally induced (4.7\%) better $C_{L} / C_{D m a x}$ magnitude than Mark 1 . Both models showed substantial decline in $\mathrm{C}_{\mathrm{L}} / \mathrm{C}_{D}$ magnitude due to massive $\mathrm{CD}$ magnitude generation at higher $\alpha$ stage $\left(2^{\circ}\right.$ to $\left.22^{\circ}\right)$. Furthermore, Mark 2 exhibited greater $C_{L} / C_{D}$ decline than Mark 1 as it generated more significant $C_{D}$ than Mark 1. Higher $C_{D}$ magnitude found in Mark 2 subsequently overwhelmed its benevolent $C_{L}$ performance, thus affecting its aerodynamic efficiency at high $\alpha$ stage $\left(5^{\circ}\right.$ to $\left.22^{\circ}\right)$.

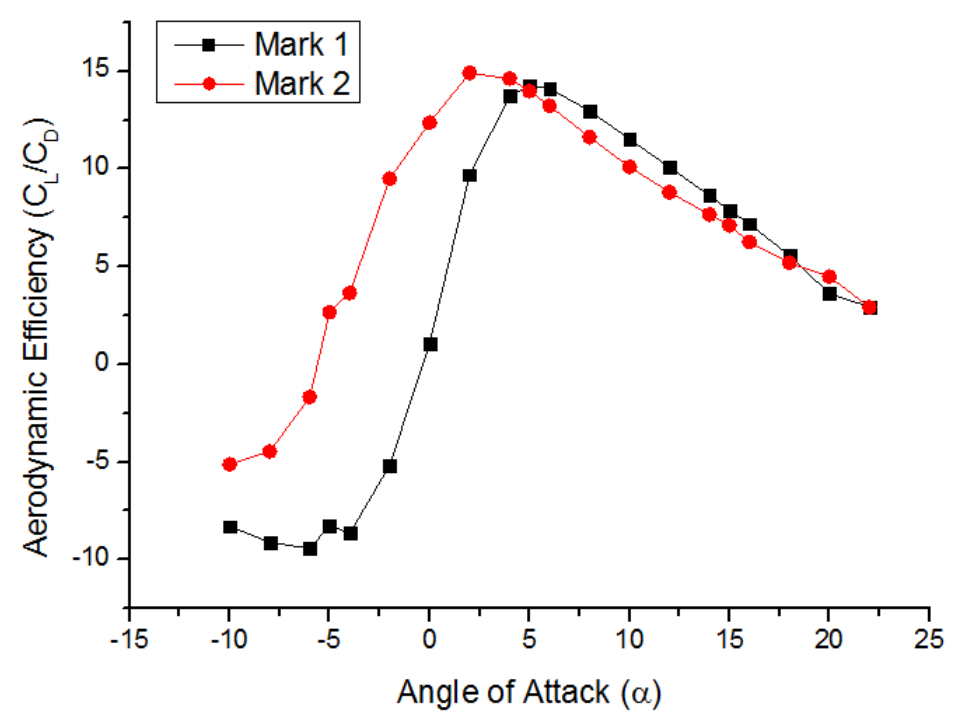

Fig. 10. $C_{L} / C_{D}$ performance for Neo-Ptero micro-UAV 


\section{Conclusions}

The main objective of this study is to investigate and compare the lift and drag characteristics between the original Neo-Ptero (Mark 1) and a new proposed Neo-Ptero (Mark 2) model. A virtual wind tunnel study on Mark 1 and Mark 2 Neo-Ptero micro-UAVs was conducted to clarify their important aerodynamics characteristics in $C_{L}, C_{D}$, and $C_{L} / C_{D}$ performances.

Based on the $C_{L}$ results, it showed that Mark 2 produced better lifting attributes, especially in $\alpha_{L=0}$, $\alpha_{\text {stall, }} C_{L \max }$ characteristics, overall $C_{L}$ magnitudes and percentage of $C_{L}$ increment. Mark 2 produced $\alpha_{\mathrm{L}=0}$ at five degrees earlier than Mark 1 at $\alpha_{\mathrm{L}=0}=-5^{\circ}$. In terms of $\alpha_{\text {stall }}$ characteristics, Mark 2 had produced better $\alpha_{\text {stall }}$ performances by delaying the stall angle at $18^{\circ}$, which is $2^{\circ}$ higher than Mark 1 $\left(\alpha_{\text {stall }}=16^{\circ}\right)$. At this $\alpha_{\text {stall }}$ angle, Mark 2 also generated better $C_{\text {Lmax }}$ magnitude at $C L_{\max }=1.24166$ which is about $35.6 \%$ higher than Mark 1. The comparison study in $C_{L}$ magnitude reveals that Mark 2 has produced at least $28 \%$ better $C_{L}$ magnitude than Mark 1 on average starts from low $\alpha$ stage (between $-10^{\circ}$ to $2^{\circ}$ ) up to high $\alpha$ stage (between $10^{\circ}$ to $16^{\circ}$ ). Mark 2 advantages continued in the $C_{L}$ increment study where the improved model had at least $8.5 \%$ better $C_{L}$ increment than Mark 1 on average at certain $\alpha$ angle. The evidence behind the improvement of $C_{L}$ characteristics on Mark 2 model is well supported through the pressure coefficient distributions study. The results showed that the lowpressure coefficient coverage area on Mark 2 surfaces is larger than Mark 1 especially at angle of attack beyond $\alpha_{\mathrm{L}=0}$. Mark 2 also had produced more significant and very low-pressure coefficient magnitude that contributed to its better $C_{L}$ performance.

Detailed analysis on the main $C_{D}$ attributes on the Neo-Ptero models revealed that Mark 2 had disadvantages in drag distributions by inducing larger $C_{D}$ magnitude and greater $C_{D}$ increment percentage than Mark 1 model at most $\alpha$ angle. However, both models produced similar $C_{D m i n}$ magnitude at 0.014 . The tip vortex study to support the $C_{D}$ attributes revealed that both models are only able to induce low $C_{D}$ magnitude at $\alpha$ below their $C_{D \text { min }}$ angle (Mark $1 \alpha=0^{\circ}$ and Mark $2 \alpha=-2^{\circ}$ ). The tip vortex core region that creates strong and intense drag attributes was kept at minimal influence at $\alpha$ below their $C_{D m i n}$ angle. However, as $\alpha$ increased beyond their $C_{D m i n}$ angle, the tip vortex core found on both models become larger and more obvious. Mark 2 induced larger tip vortex core that prohibits low drag condition and stronger intense in drag attributes compared to Mark 1.

Based on $C_{L}$ and $C_{D}$ performances, both models produced a similarity in the overall trend of $C_{L} / C_{D}$ characteristics. Nevertheless, the $C_{L} / C_{D}$ magnitude for Mark 2 is slightly greater than Mark 1 , especially in the early $\alpha$ region. Mark 2 had produced its $C_{L} / C_{D m a x}$ magnitude of 14.91 at $\alpha=2^{\circ}$ which is marginally $4.7 \%$ better $C_{L} / C_{D m a x}$ magnitude than Mark 1 . However, both models showed a substantial decline in the $\mathrm{C}_{\mathrm{L}} / \mathrm{C}$ magnitude at $\alpha$ stage beyond $2^{\circ}$. Furthermore, Mark 2 exhibited greater $C_{L} / C_{D}$ decline than Mark 1 as it generated more significant $C_{D}$ than Mark 1 . A substantial $C_{D}$ magnitude found in Mark 2 subsequently overwhelmed its benevolent $C_{L}$ performance, thus affecting its aerodynamic efficiency at $\alpha$ beyond $5^{\circ}$.

\section{Acknowledgement}

The authors would like to acknowledge technical and financial support from IFCON Technology (Malaysia) Pvt. Ltd. Authors also acknowledge laboratory and financial support from Universiti Teknologi MARA and the Government of Malaysia via the sponsorship by the Malaysia Ministry of Higher Education's Fundamental Research Grant Scheme (FRGS) (FRGS/1/2018/TK09/UITM/02/2). 


\section{References}

[1] Lee, Bohwa, Poomin Park, and Chuntaek Kim. "Power managements of a hybrid electric propulsion system powered by solar cells, fuel cells, and batteries for UAVs." Handbook of Unmanned Aerial Vehicles, ed. George J. Vachtsevanos and Kimon P. Valavanis (Dordrecht: Springer Netherlands, 2015) (2015): $495-524$. https://doi.org/10.1007/978-90-481-9707-1 115

[2] Xie, Kan, Yu Liu, and Jianren Xin. "Controlled canard configuration study for a solid rocket motor based unmanned air vehicle." Journal of Mechanical Science and Technology 23, no. 12 (2009): 3271-3280. https://doi.org/10.1007/s12206-009-0920-4

[3] Ismail, N. I., M. M. Mahadzir, A. Hasnul, M. Arif Alias, A. A. Shariffuddin, and N. I. Kamel. "Development of neoptero tailless micro aircraft." Journal of Engineering and Science Research 2, no. 6 (2018). https://doi.org/10.26666/rmp.jesr.2018.6.1

[4] Singh, Ronit K., M. Rafiuddin Ahmed, Mohammad Asid Zullah, and Young-Ho Lee. "Design of a low Reynolds number airfoil for small horizontal axis wind turbines." Renewable Energy 42 (2012): 66-76. https://doi.org/10.1016/i.renene.2011.09.014

[5] Selig, Michael S., James J. Guglielmo, Andy P. Broeren, and Philippe Giguère. Summary of low speed airfoil data. SoarTech Publications, Virginia Beach, Virginia, 1995.

[6] Lee, Bohwa, Poomin Park, Chuntaek Kim, Sooseok Yang, and Seokmin Ahn. "Power managements of a hybrid electric propulsion system for UAVs." Journal of Mechanical Science and Technology 26, no. 8 (2012): 2291-2299. https://doi.org/10.1007/s12206-012-0601-6

[7] Jindeog, Chung, Lee Jangyeon, Sung Bongzoo, and Koo Samok. "Wind tunnel test of an unmanned aerial vehicle (UAV)." KSME International Journal 17, no. 5 (2003): 776-783. https://doi.org/10.1007/BF02983873

[8] Brusov, Vladimir, Vladimir Petruchik, and Yury Tiumentsev. " Theoretical and experimental investigations of aerodynamics and flight dynamics for micro-UAVs." In 27th Congress of the International Council of the Aeronautical Sciences 2010, ICAS 2010, pp. 3164-3172. 2010.

[9] Ismail, N. I., A. H. Zulkifli, M. Z. Abdullah, M. Hisyam Basri, and Norazharuddin Shah Abdullah. "Computational aerodynamic analysis on perimeter reinforced (PR)-compliant wing." Chinese Journal of Aeronautics 26, no. 5 (2013): 1093-1105. https://doi.org/10.1016/j.cja.2013.09.001

[10] Kim, Cheolwan, and Jindeog Chung. "Aerodynamic analysis of tilt-rotor unmanned aerial vehicle with computational fluid dynamics." Journal of Mechanical Science and Technology 20, no. 4 (2006): 561-568. https://doi.org/10.1007/BF02916487

[11] Ljungskog, Emil, Simone Sebben, Alexander Broniewicz, and Christoffer Landström. "A parametric study on the influence of boundary conditions on the longitudinal pressure gradient in CFD simulations of an automotive wind tunnel." Journal of Mechanical Science and Technology 31, no. 6 (2017): 2821-2827. https://doi.org/10.1007/s12206-017-0525-2

[12] Kamas, Tuncay. "2-D and 3-D Assessment of Cambered and Symmetric Airfoils: A CFD Study." Master's Thesis, Clemson University, 2009.

[13] Zhu, Jianyang, and Jiacheng Zhang. "Power extraction performance of two semi-active flapping airfoils at biplane configuration." Journal of Mechanical Science and Technology 34, no. 1 (2020): $175-187$. https://doi.org/10.1007/s12206-019-1219-8

[14] Dwivedi, Y. D., and V. Bhargava. "Aerodynamic characterization of bio inspired corrugated wings." MOJ Applied Bionics and Biomechanics 3, no. 1 (2019): 1-10. https://doi.org/10.15406/mojabb.2019.03.00092

[15] Hoang, Ngoc TB, and Binh V. Bui. "Experimental and numerical studies of wingtip and downwash effects on horizontal tail." Journal of Mechanical Science and Technology 33, no. 2 (2019): 649-659. https://doi.org/10.1007/s12206-019-0120-9

[16] Zuan, A. M. S., A. Ruwaidab, S. Syahrullailc, and M. N. Musad. "The Effect of Adding Diffuser by Experimental." Journal of Advanced Research in Applied Mechanics 14, no. 1 (2015): 18-24.

[17] Visbal, Miguel, Turgut O. Yilmaz, and Donald Rockwell. "Three-dimensional vortex formation on a heaving lowaspect-ratio wing: Computations and experiments." Journal of Fluids and Structures 38 (2013): 58-76. https://doi.org/10.1016/i.jfluidstructs.2012.12.005

[18] Shanmugam, A. R., and C. H. Sohn. "Numerical investigation of the aerodynamic benefits of wing-wing interactions in a dragonfly-like flapping wing." Journal of Mechanical Science and Technology 33, no. 6 (2019): 2725-2735. https://doi.org/10.1007/s12206-019-0519-3

[19] Ismail, N. I., A. H. Zulkifli, R. J. Talib, H. Yusoff, and M. Asyraf Tasin. "Vortex structure on twist-morphing micro air vehicle wings." International Journal of Micro Air Vehicles 8, no. 3 (2016): $194-205$. https://doi.org/10.1177/1756829316660321

[20] Merryisha, Samuel, and Parvathy Rajendran. "Review of winglets on tip vortex, drag and airfoil geometry." Journal 
of Advanced Research in Fluid Mechanics and Thermal Sciences 63, no. 2 (2019): 218-237.

[21] Ismail, N. I., A. H. Zulkifli, M. Z. Abdullah, M. Hisyam Basri, and Norazharuddin Shah Abdullah. "Optimization of aerodynamic efficiency for twist morphing MAV wing." Chinese Journal of Aeronautics 27, no. 3 (2014): $475-487$. https://doi.org/10.1016/i.cja.2014.04.017 